\title{
LOS RIESGOS DEL TRABAJO Y SU PREVENCIÓN
}

\author{
Hugo Cifuentes LiLlo* \\ Pontificia Universidad Católica
}

\begin{abstract}
RESUMEN: El trabajo analiza la funcionalidad de la normativa sobre accidentes del trabajo y enfermedades profesionales con la realidad productiva y empresarial actual, abordando sus nudos críticos: trabajadores independientes - Ley 20.255-, trabajo a distancia, informalidad laboral, con especial énfasis en la pequeña y mediana empresa. Se discurre sobre los desafíos y el papel que debe jugar la prevención como eje de las relaciones laborales aun en períodos de crisis económica. Finalmente, expone las obligaciones de prevención contenidas en la Ley 16.744 respecto de empleadores, trabajadores, los entes públicos de fiscalización y control.
\end{abstract}

Palabras clave: Accidentes del trabajo, riesgos laborales, prevención, seguro social.

\begin{abstract}
The paper analyzes the functionality of the legislation on work accidents and occupational diseases in the reality of production and business today, addressing its critical problems: self-employed workers -Law 20. 255-, distance work, informal work, with special emphasis on small and medium company. It runs on the challenges and the role that prevention must play as the axis of the labor relations even in times of economic crisis. Finally, sets out the obligations of prevention contained in Law 16. 744 on employers, workers, public authorities of monitoring and control.
\end{abstract}

Key words: Work accidents, labor risks, prevention, social security.

\section{PRELIMINARES}

El seguro social por accidentes del trabajo y enfermedades profesionales, regulado por la ley $N^{\circ} 16.744$, se encuentra en pleno vigor, con un relevante grado de legitimidad y eficiencia. Es más se trata de un régimen de seguridad social que ha permanecido en aplicación sin transformaciones sustanciales ya por más de 42 años.

El régimen de protección establecido por la normativa de 1968, fue moderno y consistente con los sistemas de seguridad social vigente a esa época tanto en nuestro país, como a nivel comparado. Es, además, un régimen de protección social, en lo esencial y principal, apropiado para el Chile actual. El cual, sin embargo y como es natural, requiere ser sometido a revisión y adecuación en diversos aspectos de su configuración y de su regulación operativa, de forma que siga cumpliendo las funciones. que se esperan de él, en esta ya entrante segunda década del siglo XXI.

Chile cuenta, en general, con un adelantado sistema de seguridad social especialmente en el nivel de cobertura, particularmente en pensiones conforme los pilares de protección social vigentes. En materia de prevención, seguridad y salud en el trabajo, se requiere la revisión de su normativa, atendida la estructura de los mercados laborales y de la economía, así como del crecimiento que el país ha experimentado en las últimas décadas. En este, como en otros aspectos de seguridad social -protección de la salud, por ejemplo-, Chile tiene una

\footnotetext{
* A propósito de la odisea en la mina San José y la Comisión Asesora Presidencial para la Seguridad en el Trabajo. Abogado, Doctor en Derecho de Seguridad Social. Profesor universitario. Director de la OISS.
} 
Hugo Cifuentes Lillo / Los riesgos del trabajo y su prevención

oportunidad de efectuar reformas. Para la concreción de esta aspiración se cuenta con literatura, una Comisión Presidencial designada al efecto e importante experiencia comparada.

Entre estas últimas figura la Estrategia Iberoamericana de Seguridad y Salud en el Trabajo, EISST, desarrollada y promovida por la Organización Iberoamericana de Seguridad Social, OISS, cuyo contenido seguiremos en este estudio. Como Anexo I, se incluye una relación de los objetivos planteados por la EISST ${ }^{1}$.

Entre los aspectos que requieren de consideración y revisión se encuentran los siguientes:

- Elaboración de una estrategia política horizontal de prevención para todo el país y todas las áreas productivas y de servicios, debidamente integrada y coordinada.

- Definición de la autoridad o entidad encargada de orientación de la prevención.

- La coordinación entre las entidades gestoras, fiscalizadoras y los distintos entes encargados de prevención.

- Rol del tripartidismo en la elaboración de políticas y planes de ejecución en materia de prevención.

- La estandarización, mejoramiento y tecnificación de los instrumentos de registro y elaboración estadística de accidentes y enfermedades profesionales, concentrandó su gestión en lo posible un una sola entidad.

- La extensión de los comités paritarios u otros instrumentos o mecanismos de corresponsabilidad en la prevención en las pequeñas empresas, en concreto en aquellas cuyo número de trabajadores no resulta actualmente obligada a constituir el Comité.

- Mecanismo particular de medición de la tasa de riesgos de las pequeñas empresas.

- Eventualmente, la creación de tipos penales específicos relativos a los riesgos laborales.

- Revisión de los planes de formación en prevención, tanto de los técnicos como profesionales.

- Desarrollo de una cultura por la prevención, que incluya a toda la población y en que se integren esfuerzos de entidades públicas como de gestores del seguro, orientado por un programa común.

Como se aprecia, los aspectos indicados son del todo relevantes pero no afectan a la esencia del seguro social en aplicación en el país. Ello no constituye una especial novedad, por el contrario, es coincidente, en general, con lo expuesto en la literatura existente, como se puede apreciar de la revisión de la bibliografía a que recurrimos en este trabajo. Al efecto, es especialmente relevante la documentación que recopiló la Comisión Asesora Presidencial para la Seguridad en el Trabajo y que se encuentra en la página web respectiva ${ }^{2}$.

\footnotetext{
1 Estrategia Iberoamericana de Seguridad y Salud en el Trabajo 2010-2013, EISST [ www.oiss.org ] Adoptada en el Congreso Prevencia 2009, Santiago de Chile e incorporada en la declaración de los Jefes de Estado y de Gobierno de Iberoamérica de 2009, XIX CUMBRE de Lisboa.

2 Ver página web: www.comisionderiesgoseneltrabajo.cl para obtener una mayor información del origen de la Comisión, sus integrantes y los documentos generados. A la fecha de publicación de este informe la Comisión ya debe de haber entregado u propuesta. La Comisión fue creada por el DS No 28 del 23 de agosto de 2010, del MINTRAB, publicado en el D.O. del 11 de noviembre de 2010.
} 
En el ámbito que nos compete, la preocupación por la regulación adecuada y eficiente para prevenir los riesgos del trabajo, tiene en este tiempo una ocasión propicia para que se logren los acuerdos necesarios para concretar reformas esperadas. Este es el reto de la Comisión Asesora Presidencial para la Seguridad en el Trabajo, constituida en agosto de 2010. No puede ocurrir, como indicó Pedro Contador en $1993^{3}$, que continuamente y frente a tragedias laborales se levanten voces exigiendo que el deber de prevención de las empresas sea profundizado y sometido a una adecuada fiscalización, pero que solo se traduzcan en acciones de efecto relativo y no atiendan a las dificultades que afectan a la esencia de los planes de prevención.

\section{JUSTIFICACIÓN DE UN RÉGIMEN ESPECIAL DE PRESTACIONES EN MATERIA DE RIESGOS DEL TRABAJO: LA PREVENCIÓN}

En primer lugar, debe considerarse que los riesgos ṕrofesionales son solo un subconjunto dentro de un riesgo social más amplio el cual es cubierto por los sistemas de salud y, en ese sentido, con frecuencia diversas voces han llamado a reintegrar el tratamiento normativo de los riesgos del trabajo al sistema general. No obstante, es su marcado énfasis en la prevención lo que da su carácter específico, y justifica la autonomía del seguro social de accidentes del trabajo y enfermedades profesionales ${ }^{4}$. Es, entonces, la prevención el elemento central que permite mantener la autonomía del seguro social respecto del sistema de salud.

La prevención es definida por el Diccionario de la Real Academia de la Lengua Española -RAE-, como la acción y efecto de prevenir. Preparación y disposición que se hace anticipadamente para evitar un riesgo o ejecutar una cosa. Preparar, aparejar y disponer con anticipación un daño o un perjuicio. Precaver, evitar estorbar o impedir una cosa, advertir, disponer con anticipación.

La legislación nacional no ha abordado la tarea de conceptualizar la prevención, pero la doctrina ha considerado variadas alternativas. Así, se le puede considerar una actividad compleja destinada a poner a cubierto a los trabajadores de una contingencia social, el accidente o enfermedad calificado como del trabajo. Su cumplimiento representa una fórmula que impide que se verifiquen los estados de necesidad consecuentes ${ }^{5}$.

Visto desde una perspectiva más pragmática, la prevención es la técnica aplicada a la detección, evaluación y control de los riesgos potenciales presentes en el ambiente laboral y que pueden afectar al individuo o a los equipos o instalaciones. Representa el control de la manera de actuar del hombre, de la máquina y del entorno, implicando a la vez las ideas de evitar el riesgo y de corregir las condiciones y circunstancias de inseguridad ${ }^{6}$. La acción de prevenir es siempre una actividad permanente.

Es el control sobre el medio de trabajo lo que permite la introducción de incentivos y penalizaciones, así como el desarrollo de actividades específicamente orientadas a la preven-

\footnotetext{
${ }^{3}$ Contador Abraham, Pedro. La Prevención de Riesgos en la Ley de Accidentes del Trabajo y Enfermedades Profesionales No 16.744. Santiago: Editorial Jurídica de Chile, 1993, p. 14.

${ }^{4}$ Novoa F., Patricio. Derecho de Seguridad Social. Santiago: Editorial Jurídica de Chile, 1977, pp. 335-336.

${ }^{5}$ Contador Abraham, Pedro, op. cit. (n. 3), p. 27.

6 Ibid.
} 
Hugo Cifuentes Lillo / Los riesgos del trabajo y su prevención

ción, las cuales no podrían desarrollarse convenientemente en el contexto del sistema general de salud, o al menos, encontrarían dificultades. Ello justifica la posibilidad de exigir su modificación a fin de evitar el acaecimiento de los siniestros, más propiamente contingencias, lo cual redunda en la creciente importancia de la salud ocupacional o medicina en el trabajo. Ella es definida en un informe mixto de la OIT/OMS, como una rama de la salud pública que trata especialmente de la prevención de los riesgos ambientales en los lugares de trabajo, del control de las enfermedades ocupacionales y accidentes del trabajo y de la adaptación del trabajador a sus labores ${ }^{7}$. Sus objetivos se encuentran expresados en la Recomendación No 112 de 1959 de la OIT, consistiendo en:

"tratar de promover y mantener el mayor grado de bienestar físico, mental y social de los trabajadores en todas las profesiones; prevenir todo daño causado a la salud de estos por las condiciones de su trabajo, protegerlos en su empleo contra los riesgos resultantes de la presencia de agentes perjudiciales para la salud; colocar y mantener al trabajador en un empleo adecuado a sus capacidades fisiológicas y psicológicas y, en suma, adaptar el trabajo al hombre y cada hombre a su trabajo"8.

Deriva de la salud ocupacional la ergonomía, la cual estudia desde una perspectiva técnico-biológica la adaptación entre el hombre, equipo y entorno, en este caso, en el trabajo. La recepción de esta última debería adquirir mayor relevancia en los procesos preventivos que la que hasta hoy ha alcanzado.

\section{ASPECTOS DEL SEGURO SOCIAL QUE REQUIEREN ESPECIAL CONSIDERACIÓN}

La regulación del seguro social de accidentes de trabajo y enfermedades profesionales chileno, se ha estructurado en torno a la cobertura de los trabajadores dependientes, en particular respecto de aquellos que ejercen sus funciones en un ambiente o recinto definido por el empleador y bajo su observación más o menos directa. Se consideran también algunas situaciones en que el trabajador presta el servicio - parcial, transitoria o de forma relativamente permanente-, en recintos o espacios diferentes al lugar físico de la empresa y no supervisables por el patrón de forma inmediata, como es el caso de los accidentes ocurridos con ocasión del empleo ${ }^{9}$ (el caso del junior) y, en particular, los llamados in itinere ${ }^{10}$. Asimismo,

\footnotetext{
7 CONTADOR ABRAHAM, Pedro, op. cit. (n. 3), p. 22.

${ }^{8}$ Ibid.

${ }^{9}$ El accidente con ocasión, es tratado por la ley $\mathrm{N}^{\circ} 16.744$, Artículo 5 . La SUSESO ha desarrollado dentro de sus competencias, una amplia jurisprudencia a partir de los diferentes casos que se presentan para su resolución.

${ }^{10}$ Ley $\mathrm{N}^{\circ} 16.744$, Artículo 5 , inciso segundo. La ley señala que también son accidentes del trabajo los ocurridos en el trayecto directo, de ida o regreso, entre la habitación y el lugar de trabajo, y aquellos que ocurran en el trayecto directo entre dos lugares de trabajo, aunque correspondan a distintos empleadores. Ha sido la jurisprudencia, especialmente administrativa emanada de la SUSESO, la que ha delimitado el concepto, entendiéndose por trayecto directo, aquel más racional, habitual y que no ha sufrido interrupciones.
} 
en Chile, se consideran accidentes del trabajo los ocurridos a los dirigentes sindicales en el ejercicio de sus funciones ${ }^{11}$. Pero existen trabajadores cuya cobertura no se ha podido lograr adecuadamente, como es el caso de los independientes. Por su parte, con el desarrollo de nuevas forma de cumplimiento de la obligación de prestar el servicio, surge también, un reto con la prevención de riesgos para aquellos trabajadores que prestan sus servicios a través de la fórmula conocida como "a distancia". Por último, existe un aspecto de relevancia en la prevención que tiene que ver con los trabajos pesados.

Efectuaremos algunas consideraciones en torno a cada uno de ellos, partiendo por el último mencionado.

\section{A)}

\section{TRABAJOS PESADOS Y RIESGOS DEL TRABAJO}

Existe una débil línea entre los riesgos que genera el trabajo y los empleos penosos, toda vez que en estos últimos, por sus condiciones inherentes, la siniestralidad laboral aumenta ${ }^{12}$. Una adecuada evaluación de tales puestos desde la perspectiva de la seguridad y salud en el trabajo puede contribuir a mejorar su tratamiento y reducir el riesgo implicado ${ }^{13}$.

Bajo la denominación de trabajos pesados, riesgosos o penosos, se incluyen empleos que su ejercicio causa un deterioro progresivo de la capacidad general de trabajo o un envejecimiento precoz, que lleva a hacer recomendable un retiro anticipado del puesto de trabajo causante de deterioro y, en general, facilitar el acceso a pensión por vejez antes de alcanzar la edad legal. Estos empleos -que por ser penosos deberían eliminarse-, tradicionalmente se mantienen por los requerimientos de la economía, compensándose el deterioro -si cabe la expresión-, por la vía un "adelantamiento" de la edad para pensionarse ${ }^{14}$. Es lo que ocurre en Chile desde los años cincuenta. En la actualidad el asunto se encuentra regulado en la ley 19.404 de $1.995^{15}$, que entre otras materias creó y reguló la Comisión Ergonómica $\mathrm{Na}$ cional, CEN, la que tiene competencia para determinar los puestos de trabajo que califican como pesados y que por consiguiente, ponen a trabajadores y empleadores en la obligación de efectuar una cotización adicional que le permita al afiliado correspondiente, generar una pensión anticipada ${ }^{16}$. Así, el trabajador que ejecuta trabajos calificados como pesados, llega

\footnotetext{
${ }^{11}$ Artículo 5, inciso tercero, ley $\mathrm{N}^{\circ} 16.744$.

12 Existe también en nuestra legislación el concepto de trabajos peligrosos o insalubres -artículos 189 y siguientes del Código del Trabajo-, el cual se solapa, pero no se confunde con el de trabajo pesado. El trabajo peligroso se rige por normativa reglamentaria adicional y requiere que los trabajadores posean un certificado médico de aptitud para el mismo, pero no necesariamente provocan un deterioro progresivo de la capacidad de trabajo.

${ }^{13}$ En este campo tiene una amplia aplicación la ergonomía. La OIT ha desarrollado un texto con los principios básicos de dicha ciencia en orden a facilitar su uso por parte de las empresas. Puede ubicarse en http://training.itcilo.it/actrav_cdrom $2 /$ es/ osh/ergo/ergonomi.html

${ }^{14}$ Así como para algunos autores la pensión por vejez es un premio, no puede tener este carácter la que se genera por la realización de trabajos pesados. "Existirá solo la constatación de que, por haber realizado tales trabajos habrá disminuido antes su capacidad de trabajo o que, por estar realizando tales trabajos, no debe continuar en ellos más allá de cierta edad, que será inferior a la que normalmente determina el derecho a pensión". NOVOA F., Patricio, op. cit. (n. 4), p. 294.

15 Reglamentada por los DS 71 y 130, ambos del 1996 del MINTRAB. Sobre trabajos pesados conforme a la regulación legal del 1995, véase SCHMIDT C., Romy. "Nuevo Sistema de Trabajos Pesados", en: Revista Laboral Chilena, No 9-10, septiembre/ octubre, 1996 , p. 65 y ss.

${ }^{16}$ DL. 3.500 de 1980 , artículo 17 bis.
} 
a generar una pensión anticipada de vejez, caracterizada por su causa y su forma de financiamiento.

\section{B) TRABAJADORES INDEPENDIENTES, RIESGOS DEL TRABAJO Y PREVENCION}

El legislador de 1968 estableció para ellos su incorporación obligatoria, pero los resultados en cuanto a su cobertura son muy escasos. Con la reforma previsional de 2008 , se los incorpora a través de un mecanismo que pretende resolver las dificultades habidas con la anterior fórmula ${ }^{17}$. Cuestión importante será revisar cómo se ejercerán las labores de prevención de riesgos en este ámbito relevante de trabajadores de producirse su incorporación masiva.

Conforme con lo dispuesto por la ley No 20.255, los trabajadores independientes obligados a afiliarse para pensiones, lo están también para el seguro social de la ley $16.744^{18}$. Obligación que estará en pleno vigor a contar del 1 de enero de 2012, con alguna salvedad. Sin duda esta regulación es un importante avance en el establecimiento de un mecanismo integral de protección para los trabajadores independientes y, por otro lado, de ordenamiento institucional y de costos, en materia de salud ${ }^{19}$. Su incorporación se efectúa en los mismo términos que la correspondiente a los trabajadores dependientes. Estos prestadores de servicios contribuyen directamente al financiamiento del seguro, tanto con la cotización básica como con la cotización adicional diferenciada, según su actividad ${ }^{20}$.

No resuelve la ley el mecanismo de incorporación de los independientes a las entidades gestoras del seguro, por lo cual correspondería aplicar las normas generales: el trabajador determina si se afilia a una Mutualidad o al SSL $^{21}$.

Por su parte, los trabajadores independientes calificados como voluntarios, es decir, las personas que realizan actividades no remuneradas y que se afilian al régimen de pensiones, pueden acceder a la cobertura de este seguro ${ }^{22}$, efectuando los aportes correspondientes, en la medida que previamente hayan realizado sus cotizaciones de pensiones y salud del mes respectivo.

\footnotetext{
${ }^{17} \mathrm{La}$ ley $\mathrm{N}^{\circ} 16.744$, por su artículo 2, originalmente establecía la afiliación obligatoria al seguro social, de todos los trabajadores independientes, quedando su incorporación efectiva entregada a decretos supremos, por los cuales el Presidente de la República, previa definición del sector de trabajadores a incorporar, determinaba la tasas de cotización adicional a aplicar conforme la actividad y lo dispuesto en el reglamento para la determinación de la cotización adicional diferenciada del artículo 15 , de la ley $N^{\circ} 16.744$, y se precisaba la forma de efectuar el recaudo de las cotizaciones.

18 Por el artículo 88, la ley dispone la incorporación de los trabajadores independientes "señalados en artículo 89 del decreto ley $N^{\circ} 3.500$, de $1980^{\prime}$ al seguro social de la ley $N^{\circ} 16.744$, es decir, los trabajadores independientes obligados a afiliarse al sistema previsional.

19 Para un estudio más detallado sobre la incorporación obligatoria de los independientes a la seguridad social, véase CIFUENTES, Hugo y WALKER, Francisco. "Aspectos Generales de la ley No 20.255 que establece una Reforma Previsional”, en: Revista Laboral Chilena No 165 , abril de 2008, pp. 88-127.

${ }^{20}$ Se admite también la incorporación al seguro de los socios de sociedades de personas, socios de sociedades en comanditas por acciones, empresarios individuales y directores de sociedades en general, que se desempeñen como trabajadores independientes en la respectiva sociedad o empresa, lo que hasta la fecha era una deficiencia del seguro en materia de cobertura.

${ }^{21}$ La Circular 2483 de 3 de diciembre de 2008, de la SUSESO detalla las condiciones y procedimientos por los cuales los trabajadores independientes que pueden voluntariamente acogerse al Seguro Social pueden ejercer tal derecho antes del 2012.

${ }^{22}$ Artículo 89 de la ley $\mathrm{N}^{\circ} 20.255$.
} 
Lo que no resulta definido es el mecanismo de prevención de riesgos del trabajo para los independientes o autónomos y los voluntarios.

\section{C) Trabajo EJECUTADO A DisTANCIA}

Corresponde plantearse cómo las modificaciones que se deben introducir en materia de seguridad y salud en el trabajo y la prevención, considerarán la situación del trabajo dependiente y subordinado a distancia, es decir, el que se realiza fuera de las dependencias de la empresa, consecuentemente, del cuidado y vigilancia directa del empleador, ya sea en el hogar o en un lugar libremente elegido por el trabajador y que cada día alcanza mayor aceptación. Tal es así que actualmente se debate en el Congreso un proyecto de ley ${ }^{23}$ que pretende regular este tipo de prestación de servicios en dependencia y subordinación.

En dicho proyecto, todo lo relativo a la prevención de riesgos, más concretamente en cuanto a las condiciones de higiene y seguridad a que se sujetarán en el cumplimiento de sus obligaciones contractuales estos trabajadores:

“serán reguladas mediante un decreto supremo dictado al efecto por el Ministerio del Trabajo y Previsión Social y suscrito además por el Ministro de Salud. El empleador solo estará obligado a comunicar por escrito al trabajador dichas condiciones. Durante la vigencia de la relación laboral, corresponderá únicamente al trabajador cumplir las condiciones de higiene y seguridad, en conformidad a las normas que establezca el referido decreto" 24 .

En principio, el desarrollo de cultura previsional y de prevención será de alta relevancia en este sector.

\section{D) INFORMALIDAD LABORAL, PYMES Y SITUACIÖN DE SECTORES LABORALES DESFAVO- RECIDOS}

Dentro de Latinoamérica, la regulación de los riesgos del trabajo, así como la efectividad de la misma es marcadamente heterogénea, encontrando diferentes niveles de evolución, desde baja cobertura y protección hasta países con un importante nivel de desarrollo, caso, entre otros, de Chile. Los avances de este ámbito y su homogenización entre los diversos Estados se ven lastrados principalmente por dos grandes factores: el tamaño de la economía informal y la falta de bases estadísticas fiables y completas, tanto en accidentes del trabajo como en enfermedades profesionales. A ello se agrega la falta de una política horizontal coordinada y la falta de difusión de los derechos/obligaciones legales, sobre todo en la PYME.

El impacto de la economía informal se relaciona íntimamente con la cobertura de la seguridad social la cual, para Latinoamérica, solo alcanza en torno a un $12 \%$ promedio ${ }^{25}$.

\footnotetext{
${ }^{23}$ Mensaje 224-358, del 20.8.2010.

${ }^{24}$ Artículo único número 3, del proyecto de ley, que introduce un nuevo Capítulo II, en Título II del Libro I del Código del Trabajo, nuevo artículo 86 bis, inciso quinto.

${ }^{25}$ Estrategia Iberoameticana de S.S., EISST, op. cit. (n. 1), p. 12, citando a la OIT.
} 
Adicionalmente, la falta de protección se concentra en aquellos grupos sociales más vulnerables -mujeres, menores de edad, etnias originarias, migrantes, adultos mayores-, incrementando sus posibilidades de sufrir un accidente laboral y quedando desprotegidos frente a su acaecimiento. Por otra parte, el desarrollo informal de actividades crea un contexto de competencia desleal para con la economía formal, tanto desde una perspectiva internacional como en el interior del propio país, provocando el denominado dumping social.

PYMES y prevención. En el contexto de este estudio y de acuerdo con la estructura económica de las naciones latinoamericanas, entre ellas la chilena, la pequeña y mediana empresa tiene un rol relevante.

Muchas de estas empresas carecen del adecuado conocimiento de la normativa de prevención, tanto en lo que respecta a derechos como a obligaciones, ya sean relativas al trabajador como al empleador, razón por la cual reviste especial importancia la promoción de la realización de actividades de capacitación y difusión de la labor preventiva. Asimismo, este tipo de unidades productivas no cuentan, en general, con la capacidad técnica ni con los recursos humanos para realizar eficazmente labores de prevención, por lo cual, de ser necesario, se recomienda por organismos internacionales ${ }^{26}$ establecer programas para el financiamiento parcial a la contratación de personal técnico especializado, a fin de facilitar el cumplimiento de las obligaciones preventivas. Ello a su vez, debiera impactar directamente en el desarrollo de una cultura laboral acorde con la seguridad en el trabajo. Aspecto este último, de alta relevancia y que desde una perspectiva de política pública, podría situarse como una actividad propia de la medicina social, a la cual se concurrir con esfuerzos y recursos tanto presupuestarios o fiscales, como de las entidades gestoras del seguros, todo integrado en una estrategia pública debidamente consensuada de forma tripartita. Las PYMES han de dejar de ser las hermanas pobres en la definición y aplicación de los programas de prevención.

\section{E) CRISIS ECONÓMICA, EMPLEO Y PREVENCIÓN}

Las situaciones de crisis económicas siempre impactan también en el ámbito de los riesgos y su prevención. Sobre este aspecto no es necesario argumentar con insistencia. Son los accidentes graves asociados a eventos generalmente trágicos los que llevan a revisar (o intentarlo) las medidas de prevención. Los gastos o costos de las medidas y programas preventivos, son hasta ahora prescindibles para la mayoría de los empleadores. Se requiere de consensos políticos adecuados para la implantación de sistemas de seguimiento de la seguridad y la salud en la empresa, asociados a sanciones, que no solo pueden ser económicas, para incentivar el cumplimiento de las normas sobre seguridad y salud en el trabajo.

Asimismo, e íntimamente ligado en sus causas a lo dicho en el párrafo anterior, la aspiración a incrementar la oferta de empleo es un incentivo que puede jugar en contra de la prevención de riesgos, por los costos asociados. Los trabajadores interesados en encontrar empleo, en circunstancias de baja e incluso de normal oferta laboral, generalmente

\footnotetext{
${ }^{26}$ En dicho sentido se encuentran tanto el Programa Global en Seguridad, de la OIT, como La Estrategia Iberoamericana de Seguridad y Salud en el Trabajo 2011-2013, EISST, op. cit. (n. 1), pp. 35-36. Las PYMES por presentar singularidades de tipo económico, de gestión y de recursos, requieren tratamiento diferencial.
} 
están disponibles a aceptarlos, sin considerar las condiciones de seguridad en la faena. Definitivamente, la calidad del trabajo -su seguridad- no se cuestiona en situaciones de bajo empleo.

En los dos ámbitos indicados, la toma de conciencia por la vía de la cultura preventiva está asociada al establecimiento de responsabilidades, no solo derivadas de la existencia del seguro social -cotizaciones y alza de ellas-y de responsabilidades a perseguir en el ámbito civil, sino que también de responsabilidades penales, en los casos que corresponda.

Pero sin duda es en el derecho a la vida y su protección, y el establecimiento de condiciones de trabajo en condiciones decentes, como indica la OIT $^{27}$ donde se encuentra en fundamento de exigir la implantación de planes de prevención y sancionar el incumplimiento de los programas de política pública definidos al efecto.

\section{F) REGISTRO DE SINIESTRALIDAD Y SU USO PARA LA DEFINICIÓN DE POLÍTICAS PÚBLICAS}

En materia de estadísticas de riesgos profesionales, lo existente en Latinoamérica es pobre o escaso, especialmente si se considera el bajo nivel de registro de accidentes -5 a $10 \%{ }^{28}$, sumado a la falta de estandarización de las variables consideradas y, en algunos casos, la inexistencia de las estadísticas relevantes. A esto se agrega el fenómeno de la subdeclaración o subnotificación de accidentes del trabajo y/o enfermedades profesionales en aquellos países que cuentan con registros más desarrollados, por parte de empleadores que buscan disminuir sus costos en los seguros respectivos o derechamente desconocen sus obligaciones en la materia y cómo cumplirlas, especialmente en las pequeñas empresas. Todo ello impacta directamente en la formulación de políticas públicas por parte de la autoridad, ya que al carecer de información real sobre la siniestralidad no puede orientar sus esfuerzos a las áreas más vulnerables, ni prever la evolución de las necesidades formativas de los sistemas preventivos, curativos y rehabilitadores, lo que resta eficacia a estos últimos.

Un registro que contribuya al diseño de políticas de seguridad y salud en el trabajo, debe contemplar fórmulas de ingreso de datos estandarizados que incluyan entre otros, causa del accidente, parte del cuerpo lesionada, días, horas, carga laboral, implementos laborales asociados, etc. Especial importancia reviste en la actualidad el seguimiento de datos de las enfermedades profesionales, el hermano pobre de la prevención. Organismos internacionales recomiendan que exista una entidad que se encargue de la integración de los datos recogidos de diferentes fuentes por diversos servicios públicos y entidades gestoras $^{29}$

\footnotetext{
${ }^{27}$ El concepto de Trabajo Decente fue introducido por la OIT a fines del siglo pasado, siendo entendido como aquel realizado bajo estándares internacionales en condiciones de libertad, igualdad, seguridad y dignidad humana, considerándose un piso bajo el cual se produce la violación de los derechos humanos en el trabajo. La memoria de don Juan Somavía, Director General de la OIT, por la cual se introduce el concepto puede encontrarse en http://www.ilo.org/public/spanish/standards/relm/ilc/ ilc87/rep-i.html/fortalecimiento

28 OISS, EISST, op. cit. (n. 1), pp. 23-24.

${ }^{29} \mathrm{Ibid}$.
} 
Hugo Cifuentes Lillo / Los riesgos del trabajo y su prevención

En Chile existe un importante reporte de carácter oficial, producido por la SUSESO. De la observación de sus ediciones anuales, se constata un paulatino progreso en la consolidación de un sistema estadístico que incluye información de todos las entidades gestoras (Mutuales, ISL, Administradores Delegados), en accidentes del trabajo, enfermedades profesionales y de siniestros mortales ${ }^{30}$. Por su parte y a contar del año 2007 , con la vigencia de la ley 20.123, los empleadores notifican directamente a los SEREMIS y a la Inspección del Trabajo, los accidentes fatales y de alta gravedad, con lo cual tanto la Dirección del Trabajo como el MINSAL, cuentan con registro de estas situaciones ${ }^{31}$.

Las tasas de siniestralidad en Chile vienen a la baja desde hace décadas, pero su registro requiere un mayor ejercicio de integración, consolidación y precisión, por una sola entidad como se dijo más arriba. Adicionalmente, hay que mejorar los formularios de registro, ya que algunos aún mantienen el ingreso de información como texto libre, sin codificaciones que faciliten lecturas para efectos estadísticos y, en definitiva, sirva en el diseño de protocolos y programa de trabajo. Sin duda, una adecuada estrategia nacional de salud y seguridad en el trabajo requiere de este apoyo de forma principal.

\section{LA LEY N 16.744 , SU REGLAMENTACIÓN Y LA PREVENCIÓN}

El legislador de 1968 destinó un título específico de la ley ordenadora del seguro a establecer, en las claves de la época pero plenamentes vigentes hoy, lo que estimó eran las personas, entidades e instrumentos adecuados para la concreción de una política de prevención. En todo caso, como veremos, existen otras disposiciones de la ley $\mathrm{N}^{\circ} 16.744$, que también deben ser consideradas, por ejemplo, al tratar de los requisitos de existencia de las Mutuales de Empleadores y condiciones que deben cumplir las empresas que cuentan con Administración Delegada ${ }^{32}$. Sin duda, una consideración de estas normas permite de manera más específica avanzar en una revisión de esas políticas para el futuro.

\subsection{LOS RESPONSABLES DE LA PREVENCIÓN CONSIDERADOS POR EL LEGISLADOR DE 1968}

La ley No 16.744 encargó a la Autoridad Sanitaria, a través de los actuales Servicios de Salud, las SEREMIS y en algunos aspectos al ISP, entre otras funciones, la supervigilancia y fiscalización de la prevención, higiene y seguridad de todos los sitios de trabajo, así como de las instalaciones sanitarias de los organismos administradores, de la forma y condiciones como se prestan las atenciones médicas y de la calidad de las actividades de prevención que realicen. Por su parte, éncomendó la supervigilancia general del seguro social a la SUSESO, con funciones relacionadas con el control superior de las entidades gestoras, la interpretación normativa, y la resolución de conflicto sobre la calificación de los riesgos del trabajo, el acceso a las prestaciones y la fiscalización de la administración de los recursos.

\footnotetext{
${ }^{30}$ A contar de 2004 es necesario notificar y registrar la accidentes con consecuencia de muerte atendido, que impactan en la tasa de cotización adicional efectiva de las empresas.

31 Artículo 76, ley $\mathrm{N}^{\circ} 16.744$.

${ }^{32}$ Artículo 12, letra c) y 72 , letra b) respectivamente, ley $N^{\circ}$ 16.744: que realicen actividades permanentes de prevención.
} 
Existen otras entidades con responsabilidad en esta materia, aunque en sectores específicos, como veremos.

En cuanto al papel de los trabajadores como sujetos de la prevención, la ley considera su participación a través de la elección de representantes en los Comités Paritarios, por medio de denuncia la ocurrencia de siniestros, también puede accionar por actuaciones culposas y dolosas en la ocurrencia de siniestros, demandando indemnizaciones. Para el caso que el accidente o enfermedad ocurra por su negligencia inexcusable, puede corresponderle pagar de una multa. Para el trabajador aquejado de una enfermedad profesional, existe el derecho exigir el traslado de lugar de cumplimiento de su obligación de prestar el servicio.

Al empleador en tanto, como principal responsable de la prevención en relación con su empresa, la ley le asigna responsabilidades relativas a la afiliación de la empresa al seguro; financiamiento del mismo -cotización-; premios y castigos por la implementación de medidas de prevención -alzas y rebajas de los aportes-; otorgar facilidades para que los trabajadores se efectúen exámenes médicos requeridos por el organismo administrador; confeccionar el reglamento de higiene y seguridad; constituir comités paritarios; instalar el departamentos de prevención de riesgo, de proceder; constituir comités paritarios de empresa y de faenas, diseñar u sistema de seguridad y salud en el trabajo en el caso de contratistas, etc. A cada uno de estos aspectos nos referimos en particular.

\subsection{ENTIDADES Y PERSONAS ENCARGADAS DE LA PREVENCIÓN}

Uno de los grandes desafíos de Chile es la adecuada coordinación de las diferentes entidades encargadas de la prevención. Este reto debe encararse primeramente por las instituciones públicas, con el desarrollo de una política transversal de prevención que integre y de la cual irradien las políticas verticales actualmente existentes. Tal es la recomendación de la Estrategia Iberoamericana de Seguridad Social, adoptada por la OISS, ya citada, que propone que cada país adopte su política específica conforme su grado de desarrollo ${ }^{33}$.

Establecida una política pública transversal en prevención, ella debe ser llevada a los diferentes estamentos encargados, tanto en las entidades gestoras del seguro, como en las empresas, integrando a las primeras a la determinación de las políticas preventivas, enfatizando las áreas más riesgosas y fijando proporciones presupuestarias y de recursos humanos que sirvan de patrón comparativo.

En la definición de la estrategia nacional, la participación o la actuación tripartita es relevante atendido los recursos y responsabilidades involucradas.

\subsubsection{Los empleadores y la prevención}

La Empresa es la que por mandato legal debe adoptar las medidas necesarias para proteger la vida y salud de los trabajadores. Este imperativo legal no pretende instituir a la empresa como un mero sujeto pasivo de obligaciones de higiene laboral, sino que debe asumir un rol activo, elaborando normas de higiene y seguridad, promoviéndolas, velando por

33 OISS. EISST, op. cit. (n. 1), pp. 8 y ss. 
Hugo Cifuentes Lillo / Los riesgos del trabajo y su prevención

su cumplimiento entre sus trabajadores, e implementando medidas o sistemas concretos de prevención de riesgos.

Las obligaciones del empleador se pueden analizar desde dos puntos de vista:

a) Obligaciones generales, que dicen relación con la adopción de medidas necesarias para que el trabajo se desarrolle en un ambiente seguro.

Entre estas figura las siguientes:

- Mantener al día los reglamentos internos de higiene y seguridad en el trabajo: Tanto el artículo 153 del Código del Trabajo, como el artículo 67/16.744, regulan la obligación, condiciones y requisitos que todas las empresas deben cumplir en relación con este reglamento, cuya existencia influye en la fijación de la tasa de cotización adicional. Asimismo, cabe tener presente que el empleador debe redactar el reglamento especial de faenas -contratistas y subcontratistas-, 183 E, del Código del Trabajo y 183 AB.

- Proporcionar a sus trabajadores los equipos e implementos de protección necesarios, según la naturaleza del trabajo a realizar.

- Implementar todas las medidas de higiene y seguridad en el trabajo que les prescriban directamente los Servicios de Salud -organismos estatales- o el organismo administrador al cual se encuentren incorporadas.

- Deben trasladar a los trabajadores afectados por una enfermedad profesional a labores en donde no estén expuestos al agente causante de la enfermedad.

- Deben informar oportuna y convenientemente a todos sus trabajadores acerca de los riesgos que entrañan sus labores y de las medidas de prevención adecuadas.

- Todos los lugares de trabajo deben reunir las condiciones ambientales mínimas, contempladas en la ley-Decreto Supremo N 594, de 2000-.

Todas estas relevantes acciones requieren de un cumplimiento más allá de lo formal, un rol activo del empleador e intégrado en un programa de corresponsabilidad de los actores del ámbito laboral y de la autoridad pública implicada a través de una estrategia general nacional-y específica -quizá por sectores productivos- es consistente con la responsabilidad social empresarial.

b) Constitución, organización y mantención de organismos especializados en materia de prevención de riesgos, dentro de la empresa

Según el número de trabajadores de la empresa, estas están obligadas a mantener en ellas dos tipos de organismos especializados: los Comités Paritarios de Seguridad y del Departamento de Prevención de riesgos profesionales.

Los primeros -Comités Paritarios- deben funcionar obligatoriamente en toda aquella empresa, sucursal o agencia, en que trabajen más de 25 personas. Están compuestos por tres representantes del empleador y tres representantes de los trabajadores -uno de los cuales goza de fuero-, elegidos en votación secreta y directa por estos. Sus funciones generales son las de asesorar a los trabajadores en la correcta utilización de los instrumentos de protección, vigilar el cumplimiento de las medidas de prevención; investigar las causas de los accidentes 
del trabajo y enfermedades profesionales que se producen en la empresa; decidir si el accidente o la enfermedad se debió a negligencia inexcusable del trabajador; y en general, adoptar todas las medidas necesarias para prevenir los riesgos en la empresa así como también la realización de cursos de adiestramiento destinados a la capacitación profesional de los trabajadores. La ley $\mathrm{N}^{\circ} 20.123$, estableció obligaciones adicionales, en relación la subcontratación y externalización de servicios, a propósito de los Comités Paritarios.

Los Departamentos de Prevención de riesgos profesionales, por su parte, son de constitución obligatoria en aquellas empresas mineras, industriales o comerciales que ocupen más de 100 trabajadores. Son dependencias de la empresa estando estas obligadas a su constitución. Están encargados de planificar, organizar, ejecutar y supervisar las acciones permanentes para evitar el acaecimiento de un infortunio laboral.

Las medidas específicas a adoptar dependerán de la naturaleza del trabajo a realizar en cada establecimiento. Las condiciones sanitarias y ambientales básicas que debe mantener el empleador en su lugar de trabajo se encuentran reguladas en el Código Sanitario, Libro Tercero Título III, que hace mención a un reglamento especial, constituido en la actualidad por el decreto Supremo N 594, de 1999.

Este Reglamento establece y detalla las condiciones de construcción de los locales de trabajo, así como también de suministro de servicios básicos, disposición de residuos industriales, sólidos y líquidos, de evacuación de aguas servidas, y las referentes a comedores y guardarropía ${ }^{34}$.

En materia de Comités Paritarios y rol de trabajadores y empleadores, las propuestas de la OISS en la EISSS, se orientan a reforzar su eficacia y extender esquemas de participación en empresa de menos de 25 trabajadores.

Por su parte, la ley $\mathrm{N}^{\circ} 20.123 / 2006$, incorporó el artículo 66 bis a la ley $\mathrm{N}^{\circ} 16.744$, por el cual la empresa que contrate o subcontrate a otra, debe vigilar el cumplimiento por sus contratistas o subcontratistas de la normativa relativa a higiene y seguridad, "debiendo para ello implementar un sistema de gestión de la seguridad y salud en el trabajo para todos los trabajadores involucrados, cualquiera sea su dependencia, cuando en su conjunto agrupen a más de 50 trabajadores".

Es la normativa de la ley 20.123, que introduce en el ámbito de las relaciones entre empresa principal y contratista, el concepto que debe extenderse a todos los ámbitos laborales, de sistemas de gestión de seguridad y salud en los ambientes de trabajo, ya que este es un aspecto deficitario de muestro modelo nacional de prevención ${ }^{35}$. En el Anexo II, se presenta una explicación más detallada de esta normativa que introdujo reglas específicas en materia de prevención.

Por último, conviene recordar que en la cuantía de la cotización adicional diferenciada afectiva, conforme a los artículos 15 a 17, ley $\mathrm{N}^{\circ} 16.744$ y DS. 67 de 24.11.99, se verá directamente modificada por la no adopción de medidas de prevención.

\footnotetext{
${ }^{34}$ Ver al respecto los Anexos IV, Comités Paritarios y V Departamentos de Prevención.

35 Para un mayor desarrollo revisar el artículo de GAJARDo HARBOE, María Cristina. "Obligaciones en materia de higiene y seguridad en el trabajo: los cambios de la Ley de Subcontratación”, en: Revista Laboral Chilena, No 5, mayo de 2009, pp. 81-95.
} 


\subsubsection{Los trabajadores y la prevención}

Los trabajadores son los destinatarios de la prevención de riesgos profesionales y deben ser los principales impulsores y fiscalizadores de la misma.

Toca a los trabajadores una intervención activa en estas materias, es así como, por un lado, deben observar las normas contenidas en el Reglamento Interno de Higiene y Seguridad de la empresa -artículos 67 inciso 1 de la ley y 14 del D.S. No 40-y, por el otro, tienen la facultad de formular los reparos que ese reglamento les merezca, en la forma y oportunidad que en el mismo se indica.

La ley No 16.744 contempla que los trabajadores intervengan en los Comités Paritarios que existan al interior de su empresa, instancia en la cual, dado su carácter eminentemente técnico y de composición mixta, pueden hacer presente sus inquietudes acerca de las condiciones de seguridad en que se desempeñan, proponer medidas y, de ser ello procedente, hacerlas obligatorias en su empresa.

El sindicato también tiene competencias en esta materia. Es así como se reconoce como uno de los fines principales del mismo "propender al mejoramiento de sistemas de prevención de riesgos de accidentes del trabajo y enfermedades profesionales, sin perjuicio de la competencia de los Comités Paritarios de Higiene y Seguridad, pudiendo además formular planteamientos y peticiones ante estos y exigir su pronunciamiento" 36 . No conocemos información relativa a este último aspecto, sin perjuicio que entre otros, la Central Unitaria de Trabajadores ha desarrollado programas en el ámbito de la prevención y constituyó una comisión específica para analizar la situación de la SST en el país.

$\mathrm{El}$ rol de las organizaciones sindicales, así como la de los empresarios, independiente del que compete a los trabajadores y empleador en el Comité Paritario, es de alta relevancia en la definición de las políticas nacionales sobre prevención. Hay ejemplos de acuerdos en este tema, como es el caso del plan de erradicación de la silicosis, al cual nos referiremos acto seguido. La EISST, indica como objetivo a lograr, avanzar en el protagonismo de los agentes sociales.

Atendido el carácter minero del país, y a las motivaciones de este estudio, parece pertinente referirse al programa de erradicación de la silicosis. La Ley exige que a los trabajadores sometidos al riesgo de la neumoconiosis se les efectúen exámenes semestrales -artículo 71_37. En este ámbito y en el marco del programa global de erradicación de la silicosis en el mundo al año 2030, promocionado por la OMS y la OIT, el MINSAL y el MINTRAB, definió una estrategia ${ }^{38}$, que guía el actuar de los responsables en la tarea de erradicar la

\footnotetext{
${ }^{36}$ Artículo 220 No 8 del Código del Trabajo.

${ }^{37}$ Artículo 71, ley $\mathrm{N}^{\circ} 16.744$

38 Conforme lo indicado en la Estrategia de Erradicación de la Silicosis, esta es una fibrosis pulmonar incurable y muchas veces progresiva, producida por la exposición a sílice. Conlleva discapacidad permanente y pérdida de la expectativa de vida, provoca sufrimiento humano, disminución de la calidad de vida, con importante impacto en la familia, y es una carga para la economía nacional, en términos de ausentismo laboral, pérdidas de días de trabajo, discapacidades, pago de subsidios y pérdidas de la mano de obra calificada. La Neumoconiosis, en sentido amplio, constituye una familia de enfermedades pulmonares producidas por la aspiración de materiales en suspensión -asbesto, cáñamo, sílice, etc.-. En un sentido restringido, sé trata de la enfermedad causada por la aspiración de partículas de carbón. En Chile, como país minero, la Silicosis es considerado como un problema de salud pública.
} 
silicosis, entendida como un problema de salud ocupacional. Los objetivos de la Estrategia son: disminuir y controlar la exposición a sílice en los lugares de trabajo; disminuir la incidencia y prevalencia de silicosis; mejorar el diagnóstico oportuno y el control de salud de los trabajadores con silicosis, así como el acceso a las prestaciones pecuniarias e implementar un programa de apoyo social; fortalecer el sistema de información de silicosis y de exposición a sílice y desarrollar un sistema de vigilancia, e implementar, desarrollar y evaluar un plan a través de mecanismos tripartitos que fortalezcan la participación de los trabajadores y el trabajo intersectorial. Sin duda, este plan se condice con la lógica de una Estrategia en Seguridad y Salud en el trabajo, de lo cual venimos hablando en este Trabajo.

No es descartable que en el futuro se considere la exigencia de contar "Licencias" para operar faenas en que existe riesgos ciertos de silicosis.

\subsection{ENTIDADES GESTORAS}

El seguro social es administrado y gestionado por entidades públicas y privadas. El administrador natural es el Instituto de Seguridad Laboral -ISL-39 en conjunto con los Servicios de Salud. El sector privado participa en la gestión a través de las Mutualidades de Empleadores ${ }^{40}$ y en determinadas circunstancias se autoriza una especie de autoseguro a algunas empresas a través del mecanismo de la Administración Delegada ${ }^{41}$. El empleador puede libremente determinar dónde afiliarse o adherirse para la protección de sus trabajadores. Sin esta manifestación, los trabajadores se encuentran afiliados al ISL, el cual en promedio, durante el 2009 , dio protección a 1.034 .401 trabajadores es decir, cerca del $23 \%$ de la población cubierta.

Las prestaciones médicas de los afiliados al ISL se otorgan por los Servicios de Salud y con las entidades especializadas con los cuales las convenga, incluidos los convenios con hospitales de Mutuales. Respecto de los trabajadores que en ese régimen califican como obreros, las prestaciones sanitarias deben otorgarse en los Servicios de Salud. Sin duda aquí se requiere una modificación legal.

Hoy en día las Mutualidades de Empleadores son los administradores más importantes. Del total de la población asegurada, durante el año 2009 , cerca del $75 \%{ }^{42}$ de los trabajadores $-3.575 .824-$ se encuentran afiliadas a alguna de las tres Mutuales existentes ${ }^{43}$. Dichas enti-

\footnotetext{
La Estrategia de Erradicación de la Silicosis fue convenida por los Ministerios indicados, por declaración conjunta de 13.7.2007 y a la que adhirieron autoridades públicas involucradas, entidades gestoras y representantes de los trabajadores. Dicha Estrategia consta de la publicación elaborada por las entidades responsables suscribientes, cuyo contenido hemos seguido al escribir sobre el tema.

${ }^{39}$ Creado por la ley $\mathrm{N}^{\circ} 20.255$-2008-, artículo 63 y que es el sucesor-legal del Instituto de Normalización Previsional, INP, en este aspecto.

40 Artículo 11 y ss., ley $\mathrm{N}^{\circ} 16.744$.

${ }^{41}$ Entre otros requisitos deben contar con hospitales propios y tener al menos 2.000 trabajadores permanentes, artículo 72 ley $\mathrm{N}^{\circ}$ 16.744. Hoy en día las empresas con Administración Delegada son muy pocas y el $\mathrm{N}^{\circ}$ de trabajadores afectos llega apenas a $26.278-2009-$.

42 Datos en base a Estadísticas de la SUSESO.

43 ACHS. Asociación Chilena de Seguridad; MUTUAL de Seguridad la Cámara Chilena de la Construcción e IST, Instituto de Seguridad del Trabajo. Las Mutuales son las mismas existentes al momento del establecimiento del seguro en 1968 y su ámbito de cobertura a esa época era sensiblemente más reducido.
} 
Hugo Cifuentes Lillo / Los riesgos del trabajo y su prevención

dades son corporaciones de derecho privado sin fines de lucro, creadas por los empleadores, con objeto exclusivo, que son autorizadas para actuar por el Presidente de la República y son controladas por la SUSESO, a quien la ley le encomienda la fiscalización del seguro en su integridad, sin perjuicio de las atribuciones de otros entes de control en aspectos específicos, como veremos.

\section{RESPONSABILIDAD POR LOS ACCIDENTES Y ENFERMEDADES DEL TRABAJO}

En cuanto a la responsabilidad por acontecimiento de la contingencia, nuestra legislación es comparable a la europea ${ }^{44}$, en tanto el trabajador puede acceder a las prestaciones, curativas, rehabilitadoras y reparatorias necesarias.

La protección por accidentes del trabajo y enfermedades profesionales se basa en la teoría del riesgo social, conforme a la cual corresponde a la sociedad toda hacerse cargo de los riesgos laborales, toda vez que los beneficios de la actividad laboral aprovechan no solo a la empresa, sino también, a la comunidad entera. Entonces, ante un siniestro laboral, primeramente opera la responsabilidad objetiva nacional, por la cual el afectado recibe la cobertura del seguro ${ }^{45}$, pudiendo el empleador ver incrementada su cotización adicional en base a los días laborales perdidos ${ }^{46}$. Las variaciones se aplican únicamente si el siniestro acaecido fue a causa o con ocasión de la actividad laboral, no considerándose los accidentes de trayecto y los ocurridos en cometidos sindicales, lo cual refuerza la idea del control preventivo del empleador.

Sin embargo, a pesar de basarse en la teoría del riesgo social, se reconoce la posibilidad de que el accidente o enfermedad se produzca por el actuar doloso o negligente del empleador o de un tercero, en cuyo caso, se estima que el riesgo excede los límites socialmente aceptables y haciendo responsable subjetivamente al empleador o tercero respectivo, la que para algunos siempre será excepcional, incluso pudiendo imputársela al organismo administrador, pero sin abandonar la responsabilidad objetiva frente al accidente, desplegando el seguro su actividad reparadora. La persecución de esta se complementa, permitiéndose al ente administrador respectivo repetir contra el responsable por el monto de las prestaciones que ha debido otorgar y, por su parte, facultando al trabajador o a terceros afectados por el accidente, para accionar contra los responsables de acuerdo a las prescripciones del derecho común, incluso accionando por el daño moral, conforme lo establecido en la ley en térmi-

\footnotetext{
${ }^{44}$ OISS. Informe para la Comisión Asesora Presidencial para la Seguridad en el Trabajo. Santiago 24.9.2010. p. 35. www.comisionderiesgoseneltrabajo.cl Documentos e informes.

45 La teoría del riesgo social vino a reemplazar las teorías del riesgo profesional y del riesgo de autoridad, las cuales fundamentaban la responsabilidad del empleador en el riesgo que generaba, pero permitían transferirla desde el empleador hacia el asegurador. En síntesis, expresa que la responsabilidad del siniestro compete a la sociedad toda, producto del beneficio que esta recibe de la actividad productiva. Con todo, dado que la prevención de los riesgos se focaliza en la empresa y ella es el fundamento del tratamiento diferenciado, el costo de la cobertura del seguro es puesto de cargo del empleador. Respecto a las diferentes teorías que fundamentaron la responsabilidad por los accidentes del trabajo véase GAJARDO HARBOE, María Cristina. Responsabilidad por Accidentes del Trabajo. Charla dictada el 8 de septiembre de 2009 en el Colegio de Abogados de Chile A.G. ${ }^{46} \mathrm{La}$ reglamentación de este procedimiento establece una mecánica para contabilizar las muertes como días perdidos.
} 
nos muy generales, lo cual ha dado lugar a reformas legales ${ }^{47}$ y a una abundante y no pacífca jurisprudencia.

Basándose la responsabilidad en el deber de cuidado del empleador, tanto para con sus trabajadores como para con aquellos subcontratados o suministrados, la extensión de dicha obligación se ha considerado de forma bastante amplia, debiendo cumplirse tanto en lo teórico como en lo práctico. La jurisprudencia considera no solo la presencia de elementos de protección tangible, sino también la existencia de una supervisión efectiva y aun la formación teórica que se ha dado a los trabajadores en materia de prevención ${ }^{48}$.

Cabe destacar que la responsabilidad por la falta de prevención no se halla limitada al empleador, observándose algunos fallos que la extienden al ente administrador respectivo ${ }^{49}$.

El desarrollo jurisprudencial en estas materias es relativamente reciente para el tiempo de vigencia del seguro social y, por consiguiente, se encuentra en proceso de formación ${ }^{50}$.

Un tercer nivel de responsabilidad se refiere al ámbito penal. Actualmente, conforme al artículo 69 de la ley $\mathrm{N}^{\circ} 16.744$, la responsabilidad civil por el accidente doloso surge "sin perjuicio de las acciones criminales que procedan", las cuales corresponderán a delitos contra la vida y la integridad de las personas. Con todo, no existe en nuestro país un desarrollo de la legislación penal laboral específica, la cual ha sido una herramienta eficaz en la persecución de la responsabilidad del empleador negligente, en la experiencia comparada europea $^{51}$, si bien un tipo penal por deficiencias en la prevención se situaría en el complejo campo del dolo eventual antes que en el del directo ${ }^{52}$.

La creación de un tipo penal que persiga el actuar negligente en el cumplimiento de la prevención, con resultados de menoscabo de la integridad del trabajador, junto con la

\footnotetext{
${ }^{47}$ La ley $N^{\circ} 19.447$ modificó el artículo 420 del Código del Trabajo a fin de definir la competencia de los tribunales civiles y laborales frente a las demandas indemnizatorias fundadas en accidentes del trabajo. Para mayor información al respecto véase CIFUENTES LILlO, Hugo. "Imputación de responsabilidades por los siniestros del trabajo y su prevención", en: Revista Laboral Chilena $\mathrm{N}^{\circ} 162$, diciembre 2007, pp. 96 a 101.

48 "Que no se justificó suficientemente por la demandada que se proporcionara habitualmente a los trabajadores elementos de seguridad. Ni que se les diera a los mismos charlas sobre los riesgos del trabajo." "... Las normas de Seguridad Social impuestas por imperativo social al empleador solo han de tenérselas por cumplidas cuando el empleador mantiene elementos materiales constantes y supervigilancia auténtica en cuanto a la forma como deba o haya de desarrollarse la actividad de los trabajadores, especialmente tratándose de faenas peligrosas", en: Fallos del Mes, № 503 p. 3659, año 2000-2002 y No 508, p. 278, ańo 2003, respectivamente.

49 Tal fue el caso de una auxiliar de un laboratorio radiológico, la cual sufrió una enfermedad irreversible a consecuencia de su exposición a índices de radiación sobre lo permitido. En este caso se condenó al dueño del establecimiento por violar su deber de mantener sus equipos en condiciones seguras, de modo que no representen un peligro para los trabajadores, y a la mutual a que este estaba afiliado, por no asumir adecuadamente su obligación de exigirle el cumplimiento de las medidas de seguridad para la prevención de riesgos además de no haber diagnosticado a tiempo la enfermedad que la demandante padecía, denegándole las debidas licencias. Ver más antecedentes en CURRIECO GUERRERO, Francisco Javier. Seguridad Laboral y Accidentes del Trabajo. Santiago: Editorial Jurídica ConoSur, Santiago 2001, pp. 4 y ss.

${ }^{50}$ GUMUCIO R., Juan S. "Responsabilidad civil del empleador por accidentes del trabajo en Chile", en: Revista Laboral Chilena, diciembre 1996, pp. 62-71.

51 Ver OISS. Informe para la Comisión Asesora Presidencial para la Seguridad en el Trabajo, op. cit. (n. 1), p. 34 y ss.

52 En este tipo de dolo el resultado delictivo solo aparece como posible para su autor, sin embargo el mismo se representa y acepta su acaecimiento.
} 
creación de organismos especializados en la materia -la mayoría de los países europeos tiene fiscalías especializadas en la materia ${ }^{53}$ y su coordinación con la institucionalidad existente, es una cuestión a revisar.

\section{FISCALIZACIÓN Y CONTROL}

La administración de un sistema de Seguridad Social, como la de cualquier otro, requiere siempre de una fiscalización que promueva, verifique, oriente y, en último extremo, imponga lineamientos a la gestión llevada por los administradores. Así, la fiscalización se constituye en una fuerza invasiva, pudiendo ser de origen interno o externo para el fiscalizado. No obstante, bajo esta noción tendemos a evocar la fiscalización externa, la cual desde las diversas aproximaciones que se pueden realizar, tiene por finalidad alcanzar la mayor eficiencia de la gestión institucional.

\section{A) LA SUSESO INTERPRETA Y FISCALIZA EL CUMPLIMIENTO DE LA LEY No 16.744}

El control de este Organismo comprende los aspectos médicos, sociales, financieros, actuariales, jurídicos y administrativos, razón por la cual es su facultad impartir a los administradores instrucciones obligatorias sobre estas materias. Del mismo modo, le corresponde emitir dictámenes para el mejor otorgamiento de los beneficios a los imponentes. Las principales funciones de la SUSESO son:

- Autorizar las resoluciones del ISL que confieren la administración delegada y revocar tal delegación 54 .

- Conocer de las apelaciones que se deduzcan en contra de la Comisión Médica de Reclamos, COMERE, por resoluciones que versen en cuestiones de hecho que se refieran a materias de orden médico.

- Conocer de las reclamaciones que se deduzcan en contra de las demás resoluciones que se emitan por los Administradores.

- Preparar anualmente un proyecto de presupuesto para la aplicación de seguro social y someterlo a la aprobación del MINTRAB.

- Conocer con competencia exclusiva y sin ulterior recurso los reclamos que cualquier persona deduzca ante ella por el rechazo de una licencia o reposo médico por los Servicios de Salud, Mutualidades de Empleadores e ISAPRES, basados en que la afección invocada tiene o no origen profesional.

- Conocer de reclamos por recargo de cotización adicional diferenciada aplicados por Mutualidades y Servicios de Salud.

- De oficio, requerir a sus Organos fiscalizados la remisión de los antecedentes necesarios para cumplir con su función fiscalizadora; para lo cual puede solicitar, además, la colaboración de determinados entes públicos.

- Conformar anualmente las estadísticas y el costo del seguro.

\footnotetext{
53 OISS. Informe para la Comisión Asesora Presidencial para la Seguridad en el Trabajo, op. cit. (n. 1), p. 35.

${ }^{54}$ Facultad en desuso atendido que no existen empresa que estén solicitando tal facultad y las que se mantienen son muy escasas.
} 
- Examinar los acuerdos de Directorio de las Mutualidades de Empleadores que dicen relación con fondos que invierten, deudas que condonan, solicitud de nuevos adherentes, cambios de Directorio, planes de inversiones anuales, etc.

De la relación de funciones efectuadas, surge la conveniencia de revisarlas, previa definición del rol esperado para dicha entidad de control en relación con este seguro y en particular de la prevención.

Conviene tener presente que las comperencias de la SUSESO, producto del traspaso del control del sistema de pensiones a la Superintendencia de Pensiones, se concentran principalmente en el régimen de Cajas de Compensación de Asignación Familiar, régimen de licencias médicas, algunas prestaciones de protección social y el seguro que nos ocupa.

B) Autoridad Sanitaria. La función de fiscalización COMPETE al SERVicio NACIONAL DE SALUD

Esto debe entenderse remitido a los Servicios de Salud ${ }^{55}$ :

- Supervigilar y fiscalizar la prevención de riesgos y la higiene industrial de todos los sitios de trabajo; así como el cumplimiento de las normas sobre dictación de reglamentos internos de seguridad, funcionamiento de Comités Paritarios y Departamentos de Prevención de Riesgos, pudiendo sancionar a las empresas infractoras -artículo. 65/ ley 16.744 y DS 4\%/1969/MINTRAB-;

- Disponer medidas de higiene y seguridad en determinadas empresas -artículo 68/16.744-;

- Fiscalizar las actividades de prevención de riesgos que deben realizar tanto las Mutualidades, como las empresas con Administración Delegada -artículo 65/16.744-;

- Calificar la idoneidad de toda persona para desempeñarse como experto en prevención de riesgos, ya sea profesional o práctico -artículo 4 y 9/DS $4^{\circ}$, MINSAL-;

Examinar y formular observaciones de carácter técnico para el funcionamiento de los Comités Paritarios a las empresas que no tienen Departamento de Prevención de Riesgos -artículo 15/DS 4, MINSAL y artículo 153, del Código del Trabajo-;

- Finalmente, asesorar a las empresas que no están obligadas a contar con Departamentos de Prevención, en relación al funcionamiento de los Comités Paritarios de las empresas -artículo 23/ DS No 54/969, MINTRAB-.

Sin entrar a revisar otras facultades en el ámbito de la salud, la sola observación de las indicadas, plantea cuestiones en torno a los recursos involucrados en su aplicación, cuantas de ellas se concretan, estadísticas existen al respecto, de existir, su difusión y si hay cumplimiento efectivo y no meramente formal de ellas.

C) La Dirección del Trabajo, DT

Organismo público encargado de la fiscalización de la legislación laboral, que tiene entre sus potestades algunas relativas a prevención de riesgos, entre las cuales se destacan:

${ }^{55}$ Artículo 65 de la ley $N^{\circ} 16.744$ 
sus Fiscalizadores pueden realizar visitas inspectivas a los lugares de trabajo, pudiendo ordenar la suspensión inmediata de las labores que, a su juicio, constituyan un peligro inminente para la salud o vida de los trabajadores ${ }^{56}$.

Asimismo y sin perjuicio de la amplia facultad anterior, corresponde a la Dirección del Trabajo controlar, en forma específica, la constitución y funcionamiento de los Comités Paritarios de Higiene y Seguridad que deban funcionar en las empresas -artículos 1 y 28 del DS No 54/1969/ MINTRAB-.

En el ámbito de la fiscalización en terreno, el cumplimiento asistido, más que la pura sanción tiene efectos significativos, especialmente en el ámbito de PYMES.

\section{D) Servicio Nacional de Geología y Minería, SERNAGEOMIN}

Conforme al artículo 2 No 8, DL 3.525/1980, le corresponde velar por el cumplimiento de los reglamentos de policía y seguridad minera y la aplicación de las sanciones respectivas a sus infractores; proponer la dictación de normas que tiendan a mejorar las condiciones de seguridad en las actividades mineras.

Por su parte, el artículo 2 del DS 72/1986, del Ministerio de Minería, modificado por el DS 14/992, del mismo Ministerio, que aprobó el Reglamento de Seguridad Minera, establece que sus disposiciones son aplicables, "en lo concerniente a prevención de riesgos, a todas las actividades desarrolladas en la industria extractiva minera".

El Artículo 3 del mismo Decreto establece que le corresponde al SERNAGEOMIN la competencia general en la aplicación y fiscalización de dicho Reglamento. Por su parte, el Artículo 16 del DS 72 dispone "sin perjuicio de la existencia de los reglamentos generales de seguridad e higiene industrial exigidos por la legislación vigente, las empresas deberán confeccionar y mantener, actualizados, reglamentos internos específicos de minería, que garanticen el cumplimiento de este reglamento, los cuales deberán, antes de entrar en vigencia, someterse a la aprobación del Director".

\section{E) El instituto de Salud Pública, isP}

Entre las funciones de este Instituto, se encuentran las de servir de Laboratorio $\mathrm{Na}$ cional y de Referencia en el campo de la salud ocupacional y contaminación ambiental -artículo 35/DL 2763/1979-.

\section{F) La Dirección General del Territorio Marítimo y de Marina Mercante, DIRECTEMAR}

A esta Dirección, en su carácter de Policía Marítima, le corresponde velar por el cumplimiento de las medidas de seguridad de las naves en los puertos de la República y de las faenas marítimas, fluviales y lacustre -DFL 292/1953 y DL 2222/1978-.

La revisión de las atribuciones descritas para los diferentes entes públicos indicados, pone en evidencia la necesidad de armonizarlas, coordinarlas, en el contexto de una

${ }^{56}$ DFL No 2, de 1967, del MINTRAB. 
estrategia nacional por la prevención, la seguridad y la salud en el trabajo, que por períodos acotados y responsables claramente definidos permita avanzar en los temas que nos interesan.

Un planteamiento como este implica también precisar los criterios de asignación de recursos entre las entidades públicas.

\section{OTRA NORMATIVA APLICABLE EN PREVENCIÓN}

\subsection{REGLAMENTOS DE LA LEY 16.744}

El conjunto de reglamentos dictados a partir de 1968, a fin de aplicar las normas de prevención del seguro social por riesgos del trabajo, ha debido ir adecuándose al devenir de las nuevas condiciones económico, sociales y en concreto, laborales en que toca aplicar sus disposiciones, como se aprecia de la revisión del listado que presentamos como Anexo II. Hay aquí también un importante espacio - sino el primero- para introducir reformas que permiten aplicar el seguro social conforme la realidad actual de nuestras empresas, la forma de estructurarse las faenas y características que reúne la empleabilidad, en el día de hoy.

\subsection{Código del Trabajo}

Desde la entrada en vigencia del Seguro Social al día de hoy, el legislador ha introducido una serie de normas relativas a la protección del trabajador en materia laboral, que un adecuado análisis de la situación de la prevención de riesgos del trabajo no puede dejar de considerar.

En este sentido, una de las mayores modificaciones, en los últimos años, se concretó en la regulación de las relaciones de subcontratación y suministro de personal realizado por la ley $\mathrm{N}^{\circ} 20.123$, la que amplió el rango de exigibilidad de las obligaciones preventivas, así como de los diversos cuerpos intraempresa destinados a este fin.

A su vez, el actual artículo 184 del Código del Trabajo ha sido sucesivamente ampliado, desde su versión original, a fin de dotar de mayores atribuciones fiscalizadoras a la Dirección del Trabajo, establecer obligaciones en materia informativa por parte de los organismos administradores del Seguro Social de Accidentes del Trabajo y regular la interacción entre estos, la Dirección del Trabajo y la Superintendencia de Seguridad Social en caso de constatarse deficiencias en la higiene y/o seguridad en una empresa. Dicho artículo es fundamental para analizar la responsabilidad del empleador en lo que respecta a seguridad y salud en el trabajo.

\subsection{CODIGO SANITARIO}

El libro III del Código Sanitario comprende la normativa referida a la Higiene y Salud del Ambiente y de los Lugares de Trabajo. Dicho libro, que comprende los artículos 67 a 93, se encuentra subdividido en cuatro títulos, los cuales refieren a las normas generales; la higiene y seguridad del ambiente, tanto en lo que respecta al agua y sus usos sanitarios -artículos 69 a 76- como en lo relativo a la vivienda, locales, campamentos y demás -artículos 77 a 81-; la higiene y seguridad en los lugares de trabajo -artículos 82 a 88-; y otros 
factores de riesgo, tales como la contaminación del aire, de los ruidos y de las vibraciones -artículo 89- y las sustancias tóxicas o peligrosas para la salud -artículos 90 a 93-. Con todo, gran parte de la regulación de dichas materias fue delegada a reglamentos específicos.

Adicionalmente pueden encontrarse en el Código Sanitario algunas normas relativas a los profesionales médicos encargados de la prevención, aunque en este caso el énfasis se ubica en el castigo al ejercicio ilegal de dicha profesión -artículos 54 y 113-.

\section{CONSIDERACIONES FINALES}

Conforme con lo expuesto es posible señalar las siguientes consideraciones de cierre:

1. El seguro social por accidentes del trabajo y enfermedades profesionales contenido en la Ley 16.744 , se encuentra plenamente vigente y con alto grado de legitimidad y eficiencia. Su estructura jurídica central no requiere cambios, pero sí adecuaciones y correcciones, atendida la experiencia y los requerimientos de un país en que han pasado más 40 años desde la instauración del régimen.

2. No existen antecedentes suficientes que ameriten reconsiderar la mantención del seguro social con estructura diferenciada del régimen de salud general.

3. La prevención es aspecto central de la mantención del seguro social independiente, y su configuración y actuales mecanismos de aplicación requieren revisión.

4. La prevención, la seguridad y salud en los ambientes de trabajo, forma parte del concepto de trabajo decente desarrollado por la OIT y de la responsabilidad social de la empresa.

5. El derecho al trabajo debe ser garantizado en términos y condiciones de ejercerlo con seguridad y ello es responsabilidad de la autoridad pública.

6. Junto con los estamentos representativos de trabajadores y empleadores, la autoridad pública debe ser impulsora de políticas en la materia, propiciando los diversos cambios normativos y reglamentarios necesarios para la implementación de una estrategia nacional de prevención de riegos, en que además se determinen los responsables de su ejecución.

7. La experiencia nacional y comparada muestra que es necesario revisar las entidades encargadas de la prevención sus funciones y tareas, cómo las desarrollan y cómo las coordinan entre sí. El establecimiento de un órgano rector, parece ser lo recomendable.

8. Para el diseño y evaluación de políticas de prevención, que deben ser dinámicas, es conveniente avanzar en mejorar los registros de siniestralidad y con un responsable final de su elaboración e integración. Los actualmente existentes pueden mejorarse y reordenarse a fin que la evolución, altamente positiva de la tasa de siniestralidad chilena, no sea objeto de observaciones.

9. Las empresas en conjunto con los trabajadores, a través de instancias de colaboración adecuados a cada realidad, según tipo, tamaño y mecanismos de desarrollo de sus objetivos empresariales, deben adoptar sus propios planes de prevención, con el apoyo técnico necesario. 
10. Es un aspecto en el cual también se debe avanzar, la formación de técnicos y expertos y su incorporación tanto en la gestión, asesoramiento y fiscalización..

11. Los gestores del seguro deben integrarse e involucrarse más allá de lo actualmente existente, en la definición y ejecución de los programas de prevención, con responsabilidades y asignación de recursos claramente identificables.

12. La política pública debe contener aspectos que incidan en el desarrollo de una cultura por la prevención y en la cual deben involucrarse gestores, empresarios y trabajadores.

\section{BIBLIOGRAFÍA}

CIFUENTES L., Hugo. "Imputación de responsabilidades por los siniestros del trabajo y su prevención", en: $R e-$ vista Laboral Chilena $\mathrm{N}^{\circ} 162$, diciembre 2007, pp. 96-101.

Cifuentes L., Hugo y Walker E., Francisco. "Aspectos Generales de la ley No 20.255 que establece una Reforma Previsional", en: Revista Laboral Chilena N 165, abril de 2008, pp. 88-127.

Cifuentes L., Hugo. "El Sistema de Seguridad Social chileno vigente. Visión y análisis de: Pensiones, Salud y enfermedad; Accidentes del Trabajo, Enfermedades Profesionales; Cesantía, Prestaciones familiares, Subsidios", en: Revista Laboral Chilena, números de abril y mayo 2010, pp. 63-75 y pp. 73-85, respectivamente.

Contador A., Pedro. La Prevención de Riesgos en la Ley de Accidentes del Trabajo y Enfermedades Profesionales No 16.744. Santiago: Editorial Jurídica de Chile, 1993.

Currieco G., Francisco Javier. Seguridad Laboral y Accidentes del Trabajo. Santiago: Editorial Jurídica ConoSur, 2001.

ECHEVERrfa T., Magdalena. "Los Riesgos Laborales de la Subcontratación", en: Revista Aporte al Debate Laboral No 19 , abril de 2006.

GAJARDO HARBOE, María Cristina. "Obligaciones en materia de higiene y seguridad en el trabajo: los cambios de la Ley, de Subcontratación”, en: Revista Laboral Chilena No 5, mayo de 2009, pp. 81-95.

Gajardo Harboe, María Cristina. Responsabilidad por Accidentes del Trabajo. Charla dictada el 8 de septiembre de 2009 en el Colegio de Abogados de Chile A.G.

GUMUCIO R., Juan S. "Responsabilidad civil del empleador por accidentes del trabajo en Chile", en: Revista Laboral Chilena, diciembre de 1996, pp. 62-71.

Humeres N., Héctor. Derecho del Trabajo y de la Seguridad Social. Tomo III. Derecho de la Seguridad Social $-17^{\text {a }}$ edición ampliada y actualizada-. Santiago: Editorial Jurídica de Chile, 2005.

LANATA F., Gabriela y CIFUENTES L., Hugo. Informe sobre riesgos laborales para congreso 2006 de la Sociedad Chilena de Derecho del Trabajo y Seguridad Social. Inédito.

MONTERO, Ricardo. Reflexiones sobre la gestión de la seguridad industrial. CEPIS: La Habana, 1996. [ Disponible en http://training.itcilo.it/actrav_cdrom2/es/osh/ergo/ergonomi.html ]

NovoA F., Patricio. Derecho de la Seguridad Social. Santiago: Editorial Jurídica de Chile, 1977.

SCHMidT C. Romy. "Nuevo Sistema de Trabajos Pesados", en: Revista Laboral Chilena, No 9-10, sepriembre/ octubre, 1996, pp. 65 y ss.

WALKER E., Francisco. Derecho de las Relaciones Laborales. Santiago: Editorial Universitaria, 2003.

OIT. El futuro de la protección social en América Latina: Aportes para el desarrollo económico y social en el marco de la agenda global de trabajo decente. Santiago, 2007.

OIT. Los trabajadores independientes y la seguridad social. Serie de publicaciones de la Secretaría de Seguridad Social, año IV No 4, Argentina, noviembre 2007. 
Hugo Cifuentes Lillo / Los riesgos del trabajo y su prevención

OIT. "Promoting safe and healthy jobs: The ILO Global Programme on Safety, Health and Enviroment -safework-", en: Revista Worl of Work No 63, OIT, Génova, 2008.

OIT. La Seguridad y Salud en el Trabajo: Ergonomia. [ Disponible en http://training.itcilo.it/actrav_cdrom2/es/ osh/ergo/ergonomi.html ]

OISS. ORGANIZACIÓN IBEROAMERICANA DE SEGURIDAD SOCIAL. Premio OISS. Empleo y Seguridad Social, La incidencia del desempleo, el empleo informal y las nuevas formas de empleo en la cobertura y la financiación de los Sistemas de Protección Social, Madrid, 2002.

OISS y CIEDESS. Regulación y fiscalización del los sistema de seguridad social. Santiago, CIEDESS, 2003.

OISS. Estrategia Iberoamericana de Seguridad y Salud en el Trabajo, 2010-2013. [Disponible en http://www.oiss. org/IMG/pdf/EISST_mayo2010_.pdf ]

OISS. Informe para la Comisión Asesora Presidencial para la Seguridad en el Trabajo. Santiago,. 24.09.201 [Disponible en www.comisionderiesgoseneltrabajo.cl] Documentos e informes.

SUPERINTENDENCIA DE SEGURIDAD SOCIAL. Estadísticas de seguridad social, 2009.

\section{SIGLAS}

CEN. Comisión Ergonómica Nacional

CEPIS. Centro Panamericano de Ingeniería Sanitaria y Ciencias del Ambiente

CIEDESS. Corporación de Investigaciones y Estudios de la Seguridad Social

COMERE. Comisión Médica de Reclamos

DIAT. Declaración Individual de Accidentes del Trabajo

DT. Dirección del Trabajo

DIRECTEMAR. Dirección General del Territorio Marítimo y de Marina Mercante

EISST. Estrategia Iberoamericana de Seguridad y Salud en el Trabajo

ISAPRES. Institución de Salud Previsional

ISL. Instituto de Seguridad Laboral

MINSAL. Ministerio de Salud

MINTRAB. Ministerio del Trabajo y Previsión Social

PYMES. Pequeñas y Medianas Empresas

SEREMI. Secretaría Regional Ministerial

RAE. Diccionario de la Real Academia Española

SERNAGEOMIN. Servicio Nacional de Geología y Minería

SST. Seguridad y Salud en el Trabajo

SUSESO. Superintendencia de Seguridad Social 


\begin{abstract}
ANEXOS
ANEXO I

OISS. ESTRATEGIA IBEROAMERICANA DE SEGURIDAD Y SALUD EN EL TRABAJO, EISST
\end{abstract}

\title{
OBJETIVOS
}

\section{OBJETIVOS GENERALES:}

1. Lucha contra el dumping social: avanzar en los programas públicos para promover que trabajadores y empresas se desplacen desde la economía informal hacia la economía formal.

2. Avanzar en el protagonismo de los agentes sociales en la SST.

3. Avanzar en.la mejora de la cultura preventiva.

4. Mejorar los sistemas de información y registro de los accidentes de trabajo y las enfermedades profesionales.

5. Incrementar la cooperación y la colaboración regional en materia de SST.

\section{OBJETIVOS ESPECÍFICOS:}

1. Conocer la situación de la SST de cada país integrado.

2. Reforzar el marco normativo de SST.

3. Reforzar los órganos técnicos de SST.

4. Reforzar las instituciones nacionales de inspección y control de las obligaciones preventivas.

5. Avanzar en el conocimiento de las causas de los accidentes de trabajo y de las enfermedades profesionales, así como en la valoración del riesgo laboral.

6. Promover programas de apoyo a la empresa para facilitar el cumplimiento de las obligaciones preventivas.

7. Mejorar la capacitación de los agentes implicados en la SST.

8. Promover políticas públicas de responsabilidad social.

\section{ANEXO II}

\section{RESPONSABILIDADES DE LAS EMPRESAS PRINCIPAL, CONTRATISTA Y SUBCONTRATISTAS EN MATERIA DE PREVENCIÓN}

\section{a) Para la empresa principal:}

- Velar porque se adopten las medidas necesarias para proteger eficazmente la vida y salud de los trabajadores que laboren en su obra, empresa o faena (artículo 183-E), lo cual, como se ve, es una extensión del deber de protección que pesa sobre el empleador por el artículo 184. 
Hugo Cifuentes Lillo / Los riesgos del trabajo y su prevención

- Velar por el cumplimiento de las normas de higiene y seguridad por los contratistas o subcontratistas, si subcontratan una obra, faena o servicio propios de su giro. En este punto recordemos que conforme al reglámento del artículo 66 bis de la ley 16.744 (DS 76 de 2006, MINTRAB) se entiende como propio del giro todo proyecto, trabajo o actividad destinado a que la empresa principal desarrolle sus operaciones o negocios cuya ejecución se realice bajo su responsabilidad, en un área determinada, edificada o no, con trabajadores sujetos a régimen de subcontratación ${ }^{57}$.

- Implementar un Sistema de Gestión de la Seguridad y Salud en el Trabajo, cuando en conjunto la empresa agrupe más de 50 trabajadores cualesquiera sea su dependencia $^{58}$.

- Confeccionar un reglamento especial para empresas contratistas y subcontratistas. Mantener un registro actualizado de antecedentes.

- Velar por la constitución y funcionamiento del Comité Paritario de Faena y del Departamento de Prevención de Riesgos de Faena.

\section{b) Para la empresa usuaria personal suministrado:}

- Responsabilidad directa en el cumplimiento de las normas de higiene y seguridad, incluidas las disposiciones legales y reglamentarias de la ley 16.744.

- Responder por las obligaciones derivadas de la responsabilidad dolosa o culposa en los accidentes del trabajo.

- Velar por la constitución y funcionamiento del Comité Paritario de Faena y del Departamento de Prevención de Riesgos de Faena.

- Denunciar los accidentes del trabajo.

- Entregar el reglamento interno de higiene y seguridad.

\section{ANEXO III}

\section{REGLAMENTOS DE PREVENCIÓN}

- Prevención de Riesgos del Trabajo (DS 40/1969, MINSAL)

- Comités Paritarios (DS 54/1969, MINTRAB)

- Calificación y evaluación de los accidentes del trabajo y las enfermedades profesionales (DS109/1968, MINTRAB)

- Condiciones sanitarias y ambientales básicas en los lugares de trabajo (DS 594/2000, MINSAL)

- Elementos de protección personal (DS 18/1982)

- Cotización adicional diferenciada (DS 67/1999 y .DS 110/1968, MINTRAB y MINSAL)

\footnotetext{
57 Artículo 4 del D.S. No 76 de 2006 MINTRAB, reglamento del artículo 66 bis de la ley $\mathrm{N}^{\circ} 16.744$. Véase también el artículo 183-E del Código del Trabajo.

${ }^{58}$ Artículo 66 bis ley $\mathrm{N}^{\circ} 16.744$.
} 
- Estatuto Orgánico de las Mutualidades (DS 285/1969, MINTRAB). Tener presente DL 1819/1977, artículo 29, y su reglamento (DS 33/1978, MINTRAB) sobre extensión de atención médica a terceros.

- Gestión de la seguridad y salud en el trabajo (DS 76/2006, MINTRAB)

- Peso máximo de la Carga Humana (Ley 20.001).

- Protección radiológica de instalaciones radioactivas (DS 3/1985).

- $\quad$ Tabaco y su consumo (Ley 19.419).

\section{ANEXO IV}

\section{COMITÉS PARITARIOS (CP)}

En toda empresa con más de 25 trabajadores se debe constituir Comité Paritario de Higiene y Seguridad.

Los Comités se componen por tres representantes del empleador y tres de los trabajadores. Los representantes de los trabajadores se eligen mediante votación secreta y directa para todos ellos.

Los representantes de los trabajadores deben tener más de 18 años de edad; encontrarse trabajando en la respectiva industria y haber pertenecido a la empresa un año como mínimo $\mathrm{y}$, por último, acreditar haber asistido a un curso de orientación de prevención de riesgos, prestar o haber prestado servicios en el Departamento de Prevención de Riesgos.

Los miembros de los Comités Paritarios duran dos años en sus funciones, pudiendo ser reelegidos.

Las funciones de los Comités Paritarios de Higiene y Seguridad son las siguientes:

1. Asesorar e instruir a los trabajadores para la correcta utilización de los instrumentos de protección;

2. Vigilar el cumplimiento de las medidas de prevención de higiene y seguridad;

3. Investigar las causas de los accidentes y enfermedades profesionales que se produzcan en la empresa;

4. Decidir si el accidente o la enfermedad profesional se debió a negligencia inexcusable del trabajador, para los efectos de la aplicación de una multa por el Servicio de Salud respectivo;

5. Indicar la adopción de medidas de higiene y seguridad que sirvan para la prevención de los riesgos profesionales;

6. Cumplir las demás funciones que les encomiende el organismo administrador respectivo, $y$

7. Promover la realización de cursos de prevención de los trabajadores.

Las resoluciones de estos Comités, son obligatorias para el empleador y los trabajadores. Sin embargo, las empresas podrán apelar de las resoluciones de los Comités.

El Comité debe actuar de forma coordinada con el Departamento de Prevención de Riesgos. 
Existe fuero laboral, hasta el término del mandato, a favor de uno de los representantes de los trabajadores en el Comité.

\section{ANEXO V \\ DEPARTAMENTO DE PREVENCIÓN}

En las empresas mineras, industriales o comerciales que ocupan más de 100 trabajadores es obligatoria la existencia del Departamento de Prevención de Riesgos Profesionales, dirigido por un experto en prevención, el cual, a su vez, forma parte, por derecho propio (con derecho a voz pero no a voto), de los Comités Paritarios.

El Departamento de Prevención es dependencia de la empresa, y se encarga de planificar, organizar, ejecutar y supervisar acciones permanentes para evitar accidentes del trabajo y enfermedades profesionales.

La organización del Departamento depende de la magnitud de la empresa y de la naturaleza de los problemas, pero debe contar con los medios y el personal necesarios para ejecutar las siguientes acciones mínimas: reconociendo y evaluación de riesgos profesionales, control de riesgos en el ambiente o medios de trabajo, acción educativa en prevención de riesgos y de promoción de adiestramiento de los trabajadores, registro de información y evaluación estadística de resultados y asesoramiento técnico a los Comités Paritarios, supervisores y líneas de administración técnica de la empresa. 